\title{
Interview
}

\section{Transformational metadata and the future of content management - An interview with Madi Solomon of Pearson PLC}

\section{Madi Solomon}

is currently Director of Content Standards at Pearson PLC, a global publishing firm with brands that include the Financial Times, Penguin, Dorling Kindersley, Scott Foresman, Prentice Hall, Addison Wesley and Longman. As the former corporate taxonomist for The Walt Disney Company, she developed standards and practices for metadata and cataloging, and a corporate taxonomy and media ontology. Before joining Disney, she was Project Associate at the Getty Information Institute in Standards and Vocabularies, and Curatorial Assistant for the Broad Art Foundation.

ABSTRACT Metadata ingest may be one of the most costly endeavors in managing and maintaining a digital asset management system but it is well worth the effort if approached with a little innovation. Today we explore how metadata's value exceeds content in a world where information is the sandbox and everybody's a player. Journal of Digital Asset Management (2009) 5, 27-37. doi:10.1057/dam.2008.48

Keywords: metadata; taxonomy; content standards; thesaurus; Pearson; Disney

MM: We're here with Madi Solomon - Director of Content Standards at Pearson. Madi, would you start off with a little bit of your professional background?

MS: Yes. It would be a pleasure. Thank you, Michael.

I am the newly appointed director of content standards here at Pearson, based in London. Before this, I was a metadata and taxonomy consultant specializing in rich media. Most of my clients were large media companies.

Before that, I was working for the Walt Disney Company, as their corporate nomenclature taxonomist.

I actually came to Disney from the non-profit sector. I was project associate for the Getty Research Institute at the Getty Center in Los Angeles - as part of their Standards and Vocabulary Program. It was called the Information Institute when I was there, before it merged with the Getty Research Institute.
For those who may not know, that's the program that is responsible for creating and managing three thesauri - the Art \& Architecture Thesaurus, the Union List of Artists' Names and the Geographic Locations Thesaurus.
MM: Fabulous. So, Madi - what's your university degree in?

MS: I have a Fine Arts Degree from Boston University.

MM: That then led into your developing basically into what we might call a cybrarian. MS: Well, this is not something I raised my hand in third grade and said I was going to grow up to be. This career didn't exist back then. I come from an arts background; I worked as a curatorial assistant and stumbled into technology because no one else in the office knew how to change the toner in the printer.

This was my unlikely entry into technology but it sparked a huge interest. I discovered a love for computers which prompted me to pursue digital imaging for museum artworks, which was new at the time. I started creating websites and began learning more about collections management. It was in collections management that I was first introduced to the concept of metadata, which eventually led to my work at the Getty.

The Walt Disney Company was interested in somebody with a museum background who would approach their digital assets as if they were museum pieces. That was very clever of 
them. By treating something as very important, it raised the value of the asset. Boxes of old animation cells were no longer regarded as trash, but valued cultural items. Suddenly, those digital files that were stuffed on a CD and crammed under the desk were being handled with white gloves, like artifacts. It changed the perception of those assets.

That's how I evolved professionally. It wasn't logical, but it was wonderful.

MM: In many respects, your approach to digital asset management and digital assets in general comes from the asset as an artifact of the culture. MS: Exactly.

MM: Could you share with us some of the emerging best practices that relate to $D A M$ services groups - as you've seen them?

MS: As we move away from having one centralized $D A M$ repository - realizing that most companies have more than one repository - in fact, in the companies that I've worked with, there are repositories scattered on a global scale - the challenges of sharing and distributing content through one 'ubersystem' have proven untenable. It just hasn't worked. Instead, using a Services Oriented Architecture where a suite of solutions are leveraged and used as an incentive for compliance to a common set of standards seems to have traction. It's still early days. From that perspective, new rules and new roles have emerged, along with new responsibilities.

Because I'm usually at a corporate level, I am not operational, so to speak. My job is to empower the businesses. So I help create councils, working groups, task forces. I build small committees to facilitate peer-to-peer education on how to manage, access and leverage available knowledge and services. This is a different approach say, than a traditional IT project where a behemoth is erected and all must adhere to iron-clad rules.

MM: Would it be fair to say that we're now in a world where many companies - especially global firms - must simply accept the fact that they have to manage multiple repositories?

MS: Yes.

MM: That requires a federal governance structure by which to synchronize or at least harmonize these multiple and oftentimes disparate systems?

MS: Correct. Harmonize, synchronize, synthesize toward a common goal.
MM: Secondly, the actual work of a $D A M$ services group will have, typically, a deep involvement with a particular line of business. In the case of Pearson, that might be textbooks or magazines or online services. Is that a fair characterization?

MS: Yes.

MM: So from the perspective of a corporate governance innovation leader of a $D A M$ services group, what are some other general patterns or practices that you've seen?

MS: My approach to metadata is that it is a cultural device that is released in an organization to spark change. This suddenly exposes deeprooted patterns of behavior and brings them to the surface. Now we can begin to identify what changes are needed in order to position the company toward a kind of convergence. Typical things that might emerge are different types of workflows, different rules or standards, different dialects and vocabularies. You can't make these differences just go away with a brand new system. One has to rely on the people to agree to make changes. This is usually a behavioral change.

And there's the rub! You can count on the fact that most people won't agree. But at least in forming some kind of community or providing some centralized meeting place, people can begin thinking and hashing out what their future operations should look like. They begin talking to each other for the first time and learn the breadth and depth of the culture they are in. This is not technology, but it's a first step toward getting their systems to interoperate as well. The purpose of the sharing of standards is to enable the organization to discover things about other divisions, including the discovery of content that other hidden repositories may hold that they never even knew about. Suddenly, their sandbox gets bigger. MM:Yes.

So if I understand you right, what you're saying here, Madi, is that there is a creative workflow where, for the most part, you're dealing with source assets and work-in-process derivatives and renditions. At some point, the creative process concludes with finalized art or finalized text or images or video.

At that point, it is ingested into the repository to be shared with the broader group of constituents and stakeholders. In the course of the creative workflow, you'll have asset-specific metadata and workflow requirements. 
Those asset-specific workflows will be very different from one another. As they start to move toward the central repository, standards have to be embraced. So you've put together a taskforce to think through the harmonization of those asset workflows. Did I get that right? MS: Yes. Well said. Except for the centralized repository. Because there is no centralized repository. The only way to centralize anything is through common practices.

MM: Say a little bit more about that.

MS: Each of the different repositories has its own way of doing business - which serves its own immediate constituency and should absolutely be encouraged. They know what they have to do. Yet there are other repositories that do the same thing with completely divergent practices because they serve a different constituency, as you said.

Instead of having a technology solution to actually link the two systems together, an alternate path is to enable them to communicate through some kind of agreement - such as identifying certain touch points or using common standards, or what Mills Davis refers to as 'the Knowledge Plane.' Then you can explore other mechanisms to enhance interoperability - a taxonomy or a controlled vocabulary, XML, and other markup languages. It allows the repositories to teach each other - not to access the assets directly, but to converse about what's in them. And then maybe exchange an asset or two.

MM: So this really then calls attention to the need to have standards and policies for metadata, to share assets across multiple repositories.

MS: Yes.

MM: Could you take us a little deeper into what you've discovered to be the basic operating principles for creating these kinds of standards and policies?

MS: Yes. Sure. Let's define standards and policy.

I think 'Standards' are like good manners. When we leave the comfort of our own home, we tend to behave differently: we use a fork and knife, we know how to sit at a table. These are all little rules we adhere to so we can all live in a semblance of a civilized society. When we go home, we don't bother with utensils as we lie on the couch and eat pizza with our hands.

So, standards for the sake of $D A M$ business requirements are an agreement to behave in a certain way in order for us to work as

a civilized company. We'll agree to these particular practices, guidelines and rules. If one doesn't, chaos ensues.

Policy is a little different. Policy is the whip that comes from corporate. It says, 'You must do this, or you cannot go any further.'

MM: Right.

MS: That's where it gets difficult. Can you come up with one particular policy that will go across all lines of business? Certainly, in terms of financial systems - absolutely. You can say, 'You must fill this out, in order to get this amount of money.' That has to be tracked.

With metadata, and particularly with creative content, it's a little harder to come up with strong policy. That said, however, I think that more and more companies are realizing that they do have to have policies for standardizing digital asset management practices; otherwise, their business will fall into chaos.

MM: Right.

So, what does a policy look like, in that context?

MS: A policy, I think, has to be hidden in some kind of mechanism so the force is not overt. For example, in order for you to put your assets in this particular repository, these are the required metadata elements that have to be filled. That's policy.

MM: This brings us to an ongoing question that we have here at the journal. In terms of the practice of $D A M$ and more specifically the work of $D A M$ services groups and/or corporate governance bodies, how do companies define roles, responsibilities and reporting requirements of individuals in a digital asset workflow?

MS: That's a good question. I think it's one that many organizations are trying to define right now. That's certainly true here at Pearson. I can say that we're trying to identify domain experts who are able to articulate exactly what the governance process should be, from compliance to incentives to workflow coordination, but it's been difficult because these new workflows are still emerging. Everyone has an idea of how this whole thing might go, but we're guessing. Making sure that there's compliance and incentives built into a digital asset management strategy is something that is usually overlooked, and for good reason. As it's hard to foresee what challenges a new workflow 
will bring. Also, many suspend belief (and logic!) and put faith in the hope that the new $D A M$ system will take care of all that.

Right now, overall, I think that roles and responsibilities for the future haven't been defined. We're still trying to identify what needs to be done, not who is going to do it. The fact that Pearson hired a director of content standards speaks to their priorities in how they envision their future as they move forward in the digital realm. They think $I^{\prime} m$ going to do it! But I don't know many other companies that are hiring directors of content standards. I will add that there are more taxonomists today than there were three years ago.

MM: Madi, one of the things we talked about was the notion of metadata modeling. If you would, give us a little bit of background on metadata modeling and some of the things that you're now discovering are relevant to the practice of metadata modeling.

MS: I know there aren't many people who'd get very excited about metadata modeling, but I'm one of them. I think that, traditionally, metadata has been seen as a way of, capturing some important information of, in essence, a file and an object. It captures essential aspects of content or digital assets or potential digital assets I should say, because metadata has the ability to transform an asset simply by changing our perception of it. Remember the Disney story?

Traditionally, metadata has asked questions such as, 'What is it? What's it called? Where do I get it? How do I get it? How is it put together and what can I do with it?'

Metadata modeling is maturing, and information architecture is moving into some very exciting places. Metadata modeling is becoming almost three-dimensional. It's not just getting the most obvious information about the object or the asset, but all of the potential ways of it can be received - as well as all of the potential ways that it can be delivered. Metadata can also be used for identifying relating data aggregates or other kinds of content that might enhance it or bring it into a different or larger context, outside your organization.

When you marry this with other kinds of metadata modules - profiles, as you mentioned before - profiles of rights and permissions for instance - it becomes a kind of interesting
Rubik's cube that is malleable depending on what it is, who you are and where you live, and what you want to do with it.

I think that metadata models capture everything from intellectual property, processes, cognitive learning behaviors, communities everything!

MM: This suggests something we'd talked about previously, in terms of a metadata maturity model. Let me start it off by framing the first few phases of it, and then let me ask you to provide additional depth and breadth to the framework.

At Level 0 of our metadata maturity model, we have just files.

MS: Yes.

MM: Then we have Level 1, which is file attributes. Day of creation, file types, maybe some color-space information and a rudimentary description of its contents, such as you might see in one or two or three cells of an Excel Spreadsheet.

Level 2 is what we call the basic metadata profile. Who created it, what's in there, how we use it. At this point, we start in a DAM services group to develop QA frameworks. So there's an ingest/profile/catalog workflow, with various stages being profiled. We could call it Googletype search. That is where one word is worth 10000 images.

At least it's there. If someone is diligent enough, they can find stuff.

Then Level 3. We could characterize that as an IP-profiled metadata. There are some business rules and user permissions. Quite often we'll find links of a particular metadata-profiling of assets to financial systems and rights management systems. Maybe even some assetdelivery or content-delivery systems that might include some transformations of it from one file to another.

At this point, we also have a clearance workflow. Specifically, this is where we start to ask, 'Do we really have rights to this? Do we owe anybody any money if we use this? And if so, under what conditions?'

MS: Yes.

MM: So then we've got a Level 4 in our maturity model, which we could call transformational metadata.

Transformational metadata basically subsumes or includes all the previous aspects of the 
maturity model. It adds to that, then, metadata and other kinds of rules that facilitate the ondemand transformation of assets and content into more fungible or sellable forms or useful forms.

In some cases, this entails development of a faceted taxonomy. I'll ask you to explain that. As well as development of various standards such as XMP and other sorts of XML-based schemas for the treatment not just of media assets, but textual or editorial assets.

MS: Yes.

MM: Let's finish out the rest of the model, and then we'll circle back.

Level 5 is where most companies are moving, but have not yet achieved. That is metadata for networked assets. Specifically, this is whole metadata infrastructure. It really takes into account that $D A M$ or the $D A M$ services group is about supporting very explicit, multi-channel revenue streams.

Not only are the assets fluid here, but also they start to accommodate other things - such as usergenerated content and user-generated assets and user-generated metadata. As well, they allow for a whole bunch of different interactions of multiple stakeholders, around a growing nation or system of repositories and production systems.

Does that more or less fit your understanding of metadata as a maturity model?

MS: Yes.

MM: Let's go back to what I'll call 'transformational metadata.' What have you learned at Disney or are in the process of learning now in your current role at Pearson of content standards around transformational metadata?

MS: Transformational. I love that word. It allows a digital asset not just to be found, but to also be given a context from which to receive. Metadata isn't just being used to identify assets for discovery and re-purposing, we're starting to see metadata as a creative asset in itself, something that can be built on, or made into something else. Something transformational. Metadata models, taxonomies, even enterprise tagging are considered highly-valued intellectual properties because they in themselves can be commoditized as a representation of a line of business, or a domain. Information about our content is going to be more important than the content. For instance, people's behavior online indicates that they are more interested in a book's table of contents than they are in the rest of the book.

But before I jump ahead to the chaotic world of creating mash-ups using metadata, it would be wise here to mention the importance of having a clean, sound digital house first. It's the only way to gather business intelligence and track what folks are doing with your data. So, getting your digital house in order includes creating digital masters and capturing lifecycle information - for instance, where it's already been used, and how it can be used again - along with the rights and permissions. Once that information is safe, you can begin playing with surrogates or proxies and start taking metadata and marrying it with other metadata. A good example of that kind of combining is Google Earth and travel blogs.

MM: Explain that a little more.

MS: Well, there are gadgets that are well-organized data structures that can be mashed up with your content. In the case of Google Earth, you can capture a city anywhere in the world and then add your personal travelog and share this with your friends on your blog.

My favorite example is Discovery Informatics, a Purdue University collaboration from across several of their colleges that came up with an emergent data environment for chemical properties to speed up the process of experimentation. It was built to support innovative, scientific research and this was done by capturing intelligence, or metadata and taxonomies, about chemical products so that engineers and scientists could conduct experiments, not with the chemicals, but with the information about the chemicals. Did the mashup blow up? Or, did it create something new such as an adhesive that could be used for buildings materials?

MM: That parallels some work and interviews that we did in the area of self-managing, autonomic computing systems from IBM. We created a really exquisite metadata framework for discrete resources in a big server stack - as a function of having metadata profiles for each resource within an application like a database or an ERP system.

When that system failed, there was real-time tracking, as far as what discrete resource within 
a compound application actually caused the system failure.

We've taken that to the next level, whereby we're now using metadata to model the development of a new piece of software. A patch. An update. To see if the development of that new software will work, simply by modeling its behavior using metadata.

MS: That's beautiful. Metadata-modeling behavior.

MM: Metadata's no longer just descriptive in terms of what's in an asset - or performative in terms of 'How do I facilitate a search or a targeted retrieval?' Now it's moving from descriptive modeling to predictive modeling.

MS: Absolutely. Once you have your metadata model, you can release it into the world and see what happens. How does your community interact with it, what do they like about it and how do they use it?

MM: That leads us into the next phase of our maturity model of networked metadata.

Specifically, that requires a whole ecosystem, all organized around the care, maintenance and evolution of metadata.

Not just as adscript or transformational, but as something even larger in terms of developing taxonomies for awareness, consideration, trial, consumption, satisfaction and advocacy among users of content. Now we're talking about creating social metadata or metadata from a social network's perspective in the behavioral markets.

MS: Yes. You mentioned taxonomies, but what you're talking about in this realm is ontologies.

MM: Yes. Take us through that.

MS: Taxonomies give context to an object. Metadata describes the object. The object lives in a taxonomy. This helps to give the object a context - a domain. 'Where are we looking at here? What is this content really all about?'

Ontologies derive from the metaphysical philosophical term that asks, 'What exists?' MM: That could be ... 'What's the nature of its being?'

MS: Thank you. Yes. 'What's the nature of its being?' That's exactly what the ontology or taxonomy would try to answer. For instance, it is, by its nature, a chemical compound. Or it is, by its nature, entertainment that consists of a television series.
In my work with Pearson, we're asking, 'Who is this company and what's in it?' or 'What's trying to exist in this context or domain?'

We can then take the taxonomy out to the network and start to add other taxonomies or data aggregates, or even add another way of interpreting the context of our object. This takes the information of our content beyond the people who created or stewarded it - but out to the people who will consume it. They have their own context or point of view. When taxonomies are linked with each other, we form an ontology.

The Getty, for instance, has three thesauri, the Art \& Architecture Thesaurus, the Union List of Artist's Names and the Geographical Location Thesaurus, but they do not reference each other. Wouldn't it be cool if Michelangelo's David could be originally placed in a historically accurate Google Earth through the Geographical Location Thesaurus? That would be an ontology.

So once there is enough data to play with, ontologies will naturally develop. It would probably include more folksonomies, or something freer-floating, would be my guess.

If the infrastructure for that kind of delivery is made with interaction in mind, then involvement could be tracked and analyzed and returned to the home organization, and a dialog would ensue where each informs the other.

MM: So this would describe the next frontier, in terms of where many of the more mature digital asset management-based firms are moving. Yes? MS: I don't know if I could get any company to go that far, yet.

MM: Right. But that would certainly be the idea.

I'd like to circle back on a couple of other topics. We just touched upon this topic at the Level 4 Transformational Metadata. It has to do with text-mining and metadata extraction.

Can you take us through some of the various attempts and next-practices relative to doing that?

MS: Well, with any kind of text-mining or metadata extraction, I think there's a misconception that all you have to do is unleash this software and it will do everything, plus walk your dog.

Even with text-heavy content, for instance, you still have to tell the software exactly what kind of information you're looking for and 
where to put it. There's some kind of a model that has to be created in order to get the intelligence out of the text-mining. Text extraction and mining can give you a good starting point, but its intelligence-making capacity is still very limited. It is also particularly challenging when you have legacy data that has a strong traditional indexing. You'd think it would make it easier but it actually makes it harder.

With my background in rich media, which is mostly non-self-describing, metadata extraction makes for an interesting challenge. How does a text-mine interpret music, for instance? Can it tell me what genre of music it is? Not yet.

At Disney, they looked at some applications that claimed to be able to do shape-recognition. You'd think that with simple shapes in animation it would be promising, but it was not quite as mature as all had hoped. It was great at recognizing color though. If you wanted anything with a nice green field, it could find it for you. But ask it to recognize Ferdinand smelling flowers in a field and it couldn't. I'm sure that it will be able to do that in the near future, but right now I think it's still in development.

There are other companies that have deployed automatic categorization and they're finding it's a lot harder than they thought. It gets particularly challenging when you have a large legacy repository that already has deep-rooted library sciences or cataloging practices. Trying to get an automatic metadata extractor to program what it can capture is actually more work than most would anticipate.

MM: Is it still less work than doing it manually? MS: I guess once you do the initial investment it is. The initial work is hard. It's easier when you're just starting out and want a baseline for a taxonomy.

MM:Yes.

With respect to rich media, typically we're talking about video, audio and maybe some Flash animations. Can you just take us through what you understand to be the current practices for ingesting, cataloging and profiling these three types of assets?

MS: Sure.

First of all, it's not really just video any more. It could be video. It could be DVD. It could be
Blu-ray. It could be streaming. It could be streaming proxy. There are lots of different ways a moving image can be delivered.

So we're moving away from cataloging an asset by its delivery system, such as a video cartridge or a film, and focusing more on the intellectual property it represents.

But the language gets a little muddy when familiar terms become practically obsolete. We still call a movie we watch at home a 'video' even when we slide in a DVD. We still call a compilation of songs or musical tracks an 'album' although that originally referred to vinyl. Content delivery continues to change and the language we use to describe it changes, but the content remains the same. The movie we watched is still a feature film no matter how it's delivered.

That's where, of course, metadata and taxonomies come in - to allow different perspectives of that same content. Depending on how you need to see it, the metadata offers a view to the digital record or asset that makes sense to you.

But how much metadata does one capture? A moving image is 24 frames a second - you're not going to capture every single thing that happens in every frame. But how do you capture at least the essence of it?

There are some solutions in using voice-totext, but that's dependent on someone talking. Not all films have dialog. What if it's a silent film - as a lot of old Disney animated shorts are? The entire 20-min short Steamboat Willie has not one word. How does a computer extract meaning from that?

It still requires someone to add, 'This is the first appearance of Mickey Mouse, ya-da-ya-da.' Audio is the same.

MM: I'd think audio would be even more abstract and arcane. Often you have no shared, consensual reality visual of what you're hearing. MS: Yes. Exactly. But that hasn't stopped people from trying.

MM: Are there any kinds of emerging metadata standards for those rather intangible, non-visual assets?

MS: Well, there are certainly industry standards for moving images. The Library of Congress does an enormous amount of work in cataloging the moving image and defining audio-visual standards. 
But I have to ask - does Pandora.com use any of those Library of Congress standards to describe the music that they release on their site? No, they don't. They use metadata captured by musicians. Those musicians are coming up with their own standards to describe what they're hearing, such as female jazz vocals with breathy style.

MM: To me, that seems like an intuitive next-practice. You have, on the playing field, practitioners who are describing products either of their own making or that a peer has made. It's really capturing the social context, dialog, discussion and key points of one practitioner to another.

MS: Exactly. It's a peer-to-peer sharing of information. Pandora.com is a great example because they use their metadata to anticipate what a user might want to hear next. So if you like breathy jazzy female vocals, they'll serve up other tracks that have been similarly classified. I, for instance, wouldn't do a search in the same way an audio historian would.

MM: Beyond just peer-to-peer, I'm really calling attention then to the social context of practitioners. When confronting a new class of assets, the place to start modeling that asset in terms of structured, formal metadata taxonomies and ontologies is how the practitioners - among themselves - describe various facets, attributes and aspects of this. Then, building up from that, a more formal description of what they already are doing, almost on a tacit, informal basis. Does that make sense?

MS: It makes sense. If I understand you correctly, I think you're absolutely right. The practitioners, of course, are the ones who not only know the content best, but also know how it's going to be used so they know how to describe it in order to make it findable. I happen to work from the grassroots up, but the goal is convergence, where the layperson and the academic can access the same content in the prism they are most comfortable with.

MM: So at the end of the day, each community will develop their own faceted taxonomy as it relates to what it is, how we retrieve it and how we might use it. And how I might quickly message to another practitioner my creative intent, with respect to this asset.

MS: Yes. That can be broken down to some of its most salient information. What is the simplest and most basic information that you need in order to get this asset? You'd ask yourself, 'What word would I use to get this asset, if I were doing a search?'

MM:Yes. I'd like to refer back to an interview we did recently with the people over at Industrial Color. This would argue powerfully, I think, for creating and capturing metadata at the point of the file's origination.

In a photo shoot, as the 5000 images from a day's shoot come streaming off of a camera into their local computer, at that point, they're uploaded into various hot folders that tag these things automatically, in terms of the job ticket and/or the project profile.

At the moment of creation, metadata containers exist that then are populated with the actual assets. So as much of that 'project information' as possible is then encoded in the asset - perhaps even using XMP as the container for that set - as opposed to having the end system, itself.

MS:Yes. I think there's a lot of research and development going on around that type of solution. At Disney, digital production is huge and the capture of metadata straight from camera is essential. The biggest challenge is where to put all of this information once it's been captured.

The capturing of metadata is getting very creative. At ESPN, for instance ... tagging a sports event must be done quickly and efficiently, so they developed these nifty touch pads with an interface that looks a lot like a game. They tag games just by touching on the numbers and symbols. No typing. They can tag a fast-moving sports event and immediately capture key plays while they're watching it with headphones. Good taggers can watch up to three games at a time! The information from their tables gets sent to a mechanism very similar to what you described.

MM: Madi, you've built a visual grammar. MS: Yes. Grammar without words.

They're trying to figure out how to use that same thing in other realms beyond sports. MM:Yes. That makes a lot of sense from a cognitive science background. It's pretty well established that with functional magnetic brain imaging, the visual cortex of the brain processes visio-spatial data - data many times faster than you can read text. 
That suggests that creating ideograms and/or visual vocabularies would essentially leverage or exploit that fact.

MS: Wow. I didn't know that.

MM: That suggests an emerging practice, which would entail drastically accelerating this tagging. Not relying on keystrokes on the keyboard, but having a large graphic tablet perhaps with various templates for rapidly encoding assets, using this visual vocabulary and grammar. MS: Yes.

Furthermore, it would exploit a skillset that's already been developed by the next generation.

MM:Yes. It's almost as though data input is like playing a video game.

MS: Exactly.

MM: Back to transformational metadata. Could you just quickly bring us up to speed on your experience and what you've found with respect to text-mining? More specifically, treating editorial text or copyrighting as an asset? MS: Well, that's an interesting question, though I can't speak from experience. I haven't seen it yet.

What's interesting about making assumptions on what people want ... Perhaps more people read the abstracts of white papers than they do the paper and watch the trailer rather than the film. This behavior changes our assumptions of value.

MM: When you have large bodies of mixedmedia content, corporate librarians and $D A M$ services groups should think about creating tables of content as a definitive navigational structure for large groups of content.

MS: Yes. But a table isn't really navigatable.

MM: I'm really thinking of two context-making structures. One would be what you see in the back of a textbook. Your subject-matter index.

But the table of contents really is the front matter. It defines the logic underlying the organization of a book, as well as the story logic, in terms of how these things naturally progress from the general and simple to the more detailed and arcane.

MS: Yes.

MM: Does it not make sense then that content services and/or content governance would start thinking about beyond just simply ontologies? Thinking in terms of tables of content for large groups of assets?
MS: Exactly. That's what Wikipedia is, in a way: a large table of contents that references domains. That is, in essence, a structured metadata model. MM: That might be a bridge concept between transformational metadata - Level 4 in our model. And networked metadata is Level 5 . One of the ways by which we start creating networked assets is to create tables of content. It is a logically organized way of looking at 10000 or 20000 assets and related pieces of content. MS: Exactly. The more precise the table of content, the faster we can digest the information.

MM: Not only the language, but it would have the visceral, tacit knowledge to know what follows next.

MS: Yes. I'm dying to know what that might be! MM: That would be the logic or the story logic - which is really the sequencing for what logically follows one step after another. Therefore, the logic of the table of contents would reflect a practitioner's summarization of an entire body of work for another practitioner. Perhaps an apprentice who needs to get up to speed on this large, evolving body of assets. MS: Ok. Or someone who's discovering exactly 'what exists' in this area.

MM: Yes.

I'd like to shift this, next, Madi - as we start to wrap up our interview here. I'd like to talk about some of the specific actors, and their roles and responsibilities as they relate to a functioning $D A M$ services group. And perhaps outlining in that some career paths that might interest the readers of this interview.

Who's the go-to person who has overall responsibility for defining and maintaining governance of all the digital assets? Is there such a person?

MS: That person's role is still emerging. It's usually a team of people. There are the people who are managing the rights information. That's usually somebody in the legal department who understands royalties, rights, permissions and use. Then there are the keepers of the images - or the documents, or marketing briefs, or whatever: the stewards of content. They may not have responsibility for digital asset over the whole company, but they are, by far, the biggest stakeholders.

Is there one person who governs digital assets? No. It's usually a consortium of 
stakeholders, all representing their own lines of business.

Overall, there is now a new role like the one I had at Disney - called the Corporate Nomenclature Taxonomist - which allowed me to build an enterprise taxonomy, but it was much, much more than that. It was a tactical effort to bring confluence to all of the different businesses, and all of the different repositories into a common place. This was to help position the company to build a strong infrastructure so they could move toward that "networked metadata.'

Who makes all that happen? There's the technology lead. There's a taxonomy lead. There's a metadata lead. There's a rights and royalties or permissions lead. There's the project managers, the taxonomy analyst who does a lot of the vocabulary shoveling, there's the markup language specialist who helps transform the metadata into XML, RDF, OWL. It is not just one person - it's everyone in the business practically.

MM: What would distinguish the taxonomy lead from the metadata lead?

MS: The metadata lead focuses on the description of an object or a digital asset. This also includes technical metadata. Everything they can possibly find about that object or that essence.

MM: So, research skills as far as what's in the file become paramount?

MS: Not just what's in the file, but what IS the file? A book? A magazine article? An episode of Desperate Housewives?

MM: As it relates to the nature of our business and how we make money.

MS: Exactly. What is this file, what's in it, where can I get it and what can I do with it are all questions metadata should answer.

MM: Then the taxonomy lead would have his or her concern in an adjacent - perhaps parallel - area. Specifically, what?

MS: What's the language that we're going to use to populate those metadata elements? So, for me, metadata comes first. Then we populate the metadata elements. We populate them with language.

MM: The specific keywords and phrases.

MS: Exactly.

MM: So that person would probably have a computer science or library science kind of background, because we're really talking about very structured, hierarchical descriptions of things. Right?

MS: Yes. There is a discipline to building a taxonomy but I've seen people who don't have a background in either computers or in library science that do a very credible job of it. I don't have a library science degree but come from a museum background in collections management.

MM: What are some of the other skillsets or mindsets that a good corporate taxonomist would share?

MS: Information architecture is evolving. We now have Knowledge Organizers, Semantic Mark-up, Metadata Librarians and Future Media departments. We all have standards that we adhere to such as the National Information Standards Organization (NISO) guidelines (the ANSI/NISO Z39.19-2003 guidelines for the construction of monolingual thesauri). That happens to be my bible.

MM: Could you quickly, in the context of this interview, describe a thesaurus?

MS: There are many terms that are interchangeable now. A thesaurus is often called a taxonomy, but there are some subtle distinctions. A thesaurus is a structure of terms that adds a level of complexity by associating terms to each other. For example, it can link synonyms such as 'lift' and 'elevator' to a single concept. A thesaurus can link associated terms such as 'piano' and 'classical music.' 'Classical music' is not a kind of piano, nor is it a component of a piano, but one could associate these terms if it best describes your domain.

A thesaurus can be hierarchical, as can a taxonomy. I am called a taxonomist, but even here they are synonyms.

MM: Also, thesauri describe a particular set of commonly used terms for a particular practice. So for example, in the area of sociology, there'll be a thesaurus for sociology. Likewise, there will be a thesaurus for marketing. And while they may have several terms in common, often they get defined in terms of a several-paragraphs definition. Often in very different ways - linking back to the underlying history of that particular discipline or practice. Is that a fair characterization?

MS: I think in a thesaurus you're not obligated to go deeply into term definition, but 
while you're there, 'Why not?' The more information you have to describe your domain, the better.

MM: Are companies building these thesauri and wikis so that they begin to take on a structure like a Wikipedia? Or is that being built into the $D A M$ itself?

MS: Companies are integrating thesauri and wikis into their digital asset management systems, but the systems themselves don't come out of the box with these functionalities. Wikis rely on loosely structured metadata to harvest information through volunteer experts, whereas thesauri are highly structured vocabularies usually designed by a professional. In a thesaurus, a single term can have its own record, its definitions, its warranted use, and so on.

MM: Wouldn't it make sense that the record of the term as you've described it can be used to avail yourself of more of a wikipedia type of structure? Where you can open up the conversation and therefore the definition to a large group of people?

MS: Yes. I think the more mature management tools are offering that through a web user interface that allows for that kind of sharing. Back in the early days at Disney (around 2002), we developed an online wiki for vocabularies, and you know what? It bombed. No one wanted to add any definitions, let alone a comment on the use of a term. The work scenario is very different from the social web network. Perhaps we tried it too early. MM: The other thing we've tracked, Madi, is the emergence of the use of wikis and forum discussion as ways of having the conversation about an asset become part of its metadata profile.

I saw this in its fullest development in a $D A M$ system specifically designed for architectural and interior design projects. The architect I had this conversation with said, 'Well, the photo itself or the illustration itself isn't particularly useful. It's the story behind the photo or behind the design where all the value is.'

That's really an example of how the metadata - the story - the description - actually trumps the economic value of the image itself.

MS: Yes. I have a favorite slide in my presentations on metadata that highlights that very concept. How metadata adds value by guiding our perceptions. The classic story of the lost Picasso picked up at a garage sale. Without the metadata, we don't know its value.

MM: Doesn't that suggest the next practice, that as $D A M$ systems continue to emerge and metadata continues to evolve that the network is really about collecting stories? How people talk and do their jobs using a particular asset as a tool or enablement or resource.

Then the metadata is not so much about the asset, but the effect - the good-positionintended economic or productivity effect that the asset enables.

MS: Yes. How wonderful. Our brains are hardwired for storytelling, and who wouldn't want a better narrative? I think the importance of what you just said is profoundly ... transformational, because it doesn't change the content, it changes our perception of the content.

MM: It changes the mindset - and therefore, the scope of imagination - relative to how I might exploit or use this particular asset at hand.

MS: Yes. It's creative.

MM: As we then would perhaps summarize this point, the story becomes the ultimate reference and the ultimate class of metadata for then describing the asset itself. Not so much the structured stuff. In terms of the metadata, you need all of that, but it's the unstructured narrative that really puts this asset into a very specific context - be it a context of a practitioner communicating to another practitioner, or a communicator to his or her stakeholder audience.

MS:Yes. Communication is now carried out on a screen. We rarely talk to each other anymore. So how do you actually communicate these nuances to the community as a whole? That's got to be done somehow, and we rely on language, symbols, or whatever. It's all metadata. It's not so much how we deliver the asset, but how we deliver the information about the asset. MM: Any final remarks?

MS: No. We're all pioneers putting the tracks in front of the train. Let's keep in touch and see what happens.

MM: Let's end it on that note.

MS: It's been a sincere pleasure. Thank you, Michael.

MM: Thank you. 